\title{
(6) OPEN ACCESS \\ Are medical students in prehospital care at risk of moral injury?
}

\author{
Esther Murray, ${ }_{1}^{1}$ Charlotte Krahé, ${ }^{2}$ Danë Goodsman ${ }^{1}$
}

${ }^{1}$ Centre for Medical Education, Barts and The London School of Medicine and Dentistry, Queen Mary University of London, London, UK

${ }^{2}$ Department of Psychology, Institute of Psychiatry, Psychology and Neuroscience, King's College London, London, UK

\section{Correspondence to}

Dr Esther Murray, Centre for Medical Education, Barts and The London School of Medicine and Dentistry, Queen Mary University of London, London E1 2AD, UK; e.murray@qmul.ac.uk

Received 27 September 2017 Revised 4 June 2018 Accepted 8 June 2018 Published Online First 26 June 2018

\section{ABSTRACT}

Background The term 'moral injury' may be useful in conceptualising the negative psychological effects of delivering emergency and prehospital medicine as it provides a non-pathological framework for understanding these effects. This is in contrast to concepts such as burnout and post-traumatic stress disorder which suggest practitioners have reached a crisis point. We conducted an exploratory, pilot study to determine whether the concept of moral injury resonated with medical students working in emergency medicine and what might mitigate that injury for them.

Methods Structured interviews and focus groups were carried out with medical students involved in the delivery of prehospital and emergency medicine. The study was carried out at Barts and the London School of Medicine and Dentistry in May and June 2017. The data were analysed using theoretically driven thematic analysis. Results Concepts of moral injury such as witnessing events which contravene one's moral code, especially those involving children, or acts of violence, resonated with the experiences of medical students in this study. Participants stated that having more medical knowledge and a clear sense of a job to do on scene helped reduce their distress at the time. While social support was a protective factor, not all students found the process of debrief easy to access or undergo, those with more established relationships with colleagues fared better in this regard.

Conclusions The term moral injury is useful in exploring the experience of medical students in emergency medicine. More effort should be made to ensure that students effectively access debrief and other support opportunities. It is hoped that future work will be undertaken with different professional groups and explore the potential psychological and neuropsychological impact of witnessing trauma.

The term 'moral injury' emerged from work with military veterans to describe the psychological sequelae of 'bearing witness to the aftermath of violence and human carnage, 12 and can occur as a result of witnessing human suffering or failing to prevent outcomes which transgress deeply held beliefs. For some time there has been a wider concern about the moral aspects of work in healthcare, as evidenced by the body of work which builds on Jameton's writings about moral distress in nursing. ${ }^{34}$ While work on moral distress focuses on decisions made in a healthcare setting, moral injury also recognises the impact on practitioners of the nature of the traumatic event. Moral injury helps conceptualise the ways in which a person's

\section{Key messages}

What is already known on this subject

- There is an increasing awareness of the negative psychological impact of providing prehospital care and emergency medicine on practitioners.

- Not all healthcare professionals who suffer psychological harm at work will meet the criteria for post-traumatic stress disorder.

- The term 'moral injury' is useful for conceptualising psychological sequelae resulting from witnessing events which transgress deeply held beliefs.

What this study adds

- This qualitative pilot study suggests that moral injury is a term applicable to the experience of student prehospital practitioners.

- Students involved in emergency medicine may need to be more strongly encouraged to talk about their experiences.

sense of themselves and the world is disrupted by 'a betrayal of what's right'. The symptoms of moral injury include feelings of guilt and shame due to an inability to have righted the wrongs committed and can result in social isolation and emotional numbing. Social support can be useful in the management of psychological distress but where shame is an element of the distress, social contact is avoided. ${ }^{1}$ A dose-response relationship has been shown for both post-traumatic stress disorder (PTSD) and moral injury ${ }^{15}$ so that practitioners providing life-saving pre-hospital care are increasingly at risk over the course of their careers; rising numbers of violent crimes, terror attacks and mass casualty events increase this risk.

There is a growing awareness of threats to practitioner mental health in prehospital care and emergency medicine. ${ }^{6}$ Not all those who are psychologically affected by their work, even in lasting ways, will reach the threshold for diagnosis of PTSD $^{8}$ and this diagnosis is often resisted by staff until they become acutely unwell. Conceptualising individual staff as disordered, insufficiently resilient or otherwise compromised by the performance of their work is counterproductive, resulting in loss of experience and expertise from the workforce and in staff masking symptoms. It is important to explore the concept of moral injury as it may capture the experience of practitioners who do not meet the diagnostic criteria for PTSD 9 
but who are troubled by the nature of the events they have seen and it may provide a useful framework for the discussion of this psychological disturbance after witnessing/being present at traumatic events.

This research is the first to explore moral injury as a type of secondary trauma in a healthy, working population in the UK. Much has been written recently about burnout in the healthcare professions (see eg Lemaire and Wallace ${ }^{10}$ ). Maslach's pioneering work from the $1980 \mathrm{~s}^{11}$ illustrates that burnout in helping professions produces emotional exhaustion and cynicism with regard to patients, similarly compassion fatigue will result in disaffection from the job at hand and a tendency to make more mistakes. ${ }^{12}$ In addition, neural responses to witnessing pain are attenuated in physicians versus non-physicians ${ }^{13} 14$ and more experienced physicians rate pain in others as less intense than less experienced physicians ${ }^{15}$ possibly indicating a blunting of empathic responses with increasing experience and exposure to trauma which would impact on patient care and team functioning. Work in the field of PTSD and secondary trauma recognises the potentially extreme psychological states which can be the result, not just of exposure to danger and risk to the self, but also of witnessing trauma in the other. ${ }^{16}$

While secondary traumatic stress ${ }^{5}$ can and does affect providers at all levels, there is evidence to suggest that medical students may suffer more frequently, and this may be because students, in contrast with experienced staff, have fewer resources and less experience to deal with witnessing suffering. ${ }^{17}$ Thus the current research explores the experience of medical students involved in prehospital care.

The objectives of this pilot study were to explore the questions:

- Does the way in which medical students talk about their experiences in prehospital care resonate with the concept of moral injury?

- If social support can be protective, to what degree do students feel they have access to this support and want to use it?

- In this research, we sought to explore a new way of conceptualising the psychological harms which may result from the practice of prehospital and emergency medicine. The concept of moral injury offers practitioners the opportunity to think about the impacts of their work in ways which do not threaten their ability to continue to do it.

\section{STUDY DESIGN, METHODOLOGY AND DATA ANALYSIS}

The current pilot study is the first of a series across professional groups, exploring the lived experience of providing prehospital care, through the theoretical lens of moral injury. The focus group/interview schedule (box 1) was adapted for healthcare populations from previous research on moral injury in military populations. ${ }^{18}$

The study was peer reviewed in the first authors' institute and ethical approval was granted by Queen Mary University of London ethics committee. Interviews were conducted by EM, a senior lecturer and chartered and registered health psychologist with extensive experience in student support, qualitative data collection and analysis. Participants were aware of EM through her attendance at teaching symposia. The goals of the research were explained in a recruitment email sent to students on the prehospital care programme and the intercalated degree in prehospital medicine via gatekeepers such as course administrators and society secretaries. EM's interest in the area of research was also explained in the preamble to the interviews and focus groups.

\section{Box 1 Interview/focus group schedule}

1. What made you sign up for Prehospital Medicine/ Prehospital Care programme?

2. I suspect that we will have different definitions of the word 'trauma' since you have a medical background and I do not. What comes to mind when I say 'trauma' to you?

3. And can you describe what it's like to see these events when you're out with the cars/ambulances/helicopter?

4. Do you find that some types of incidents worse than others? a. What do you think makes them worse?

5. Who do you talk to about what you've seen on shift?

6. Do you ever find you're remembering particular incidents some time later?

7. If you've experienced an event which bothered you for a while after it was over, would you be able to tell us what it is about it that bothers you?

8. Does it ever seem as if you would rather not keep talking over an event with others, just work on it in your own head?

9. Do you think some people (in general, not specific people you know) feel these events more deeply than others/are more bothered by them?

10. Do you ever feel as if there are not enough resources (financial/kit/staff) to treat the cases you attend?

11. Can you remember any really excellent experiences when you've been out with the teams? Things which impressed you or impacted you?

12. What do you think being involved in Emergency Medicine brings to you as a person?

Participants were selected via a form of critical case sampling suitable for this exploratory study. ${ }^{19}$ Data were gathered via two focus groups of two participants each and one interview. Data collection is ongoing. Other students who had agreed to take part dropped out before the planned focus group took place. The interview and focus groups were held in teaching rooms on campus, audio recorded and lasted between 24 and $68 \mathrm{~min}$. No non-participants were present. No repeat interviews were carried out. Field notes were made after the interviews. Participants were offered the opportunity to amend transcripts but declined nor did they take up the opportunity to review the findings. Questions were designed to be minimally distressing for students while exploring moral injurious experiences (see box 1 Q4, Q7, Q10) and symptoms resulting from moral injury (Q6, Q9). Questions 11 and 12 explore potential protective factors as well as closing the interview in a 'safe' and positive way.

A theoretical thematic analysis ${ }^{2021}$ was carried out to explore students' perceptions of the psychosocial effects of their involvement in trauma medicine. All findings reported here are viewed through the theoretical lens of moral injury, which may preclude other readings of the texts. Data were analysed by the first author, by hand. No claims are made that data saturation has been reached since data collection is ongoing. Pseudonyms are used.

\section{RESULTS}

Five students took part in the pilot study; they described complex and vivid experiences in prehospital and emergency settings and were clearly working hard to make sense of themselves and others in this experience. Their desire to do well for their team on scene was strong and meant that their relationship with debrief was 
complicated. Students explained that they were often surprised and challenged by what made a scene memorable.

The data reported in this paper is gathered into three themes: 'What is seen on scene', 'Material versus Human Resources' and 'The Complexity of Debrief'.

\section{What is seen on scene}

Some of the concepts of moral injury, such as the impact of witnessing events which contravene a person's moral code, resonate with the students' experiences. When asked what made some scenes worse than others, students revealed that it was the 'mechanism behind what had happened' (Sarah):

'it's always the ones with the violent connotations which are the hardest to process afterwards... when it's a violent attack there's an air about it of 'God, someone else has done this and it's up to us to reverse it.' Nick

Students described themselves as more aware of the scene as a whole and its implications because they had less clinical work to do than the doctors there:

'I'm just thinking about what's happened and what's going to happen next, what's going to be the effect.' Caitlin

Students observed that sometimes others were there with a 'medical, practical head on' (Sarah) using algorithms and experience to help them manage the scene. These experienced doctors were able to notice details which students sometimes found themselves too distressed to attend to, for example in this case of a deceased patient:

'he (the doctor) was like, okay, let's look for injury patterns because that's quite useful. I just remember thinking, oh my God ... Obviously I was feeling a lot more than he was but that's just by virtue of him having — that's his job and that's his life.' Maria

One student speculated that developing medical expertise was a psychologically protective factor; they talked about the difference it made to be 'looking at scenes with their medical eyes' (Sarah) and said, for example,

'I'm not just seeing (the scenes) as 'this is horrific' I'm seeing them as 'this is your injury pattern' and it changes for me the way the scenes feel.' Sarah

These observations from students suggest that while witnessing events can indeed be distressing, becoming more experienced allows them to use clinical knowledge to make sense of what is happening and thus better manage their feelings.

\section{Material versus human resources}

When asked if they had ever found there was a lack of resources to support patients at a scene, students generally had incidents they could refer to such as the lack of availability of ambulances or supplies when shifts are changing:

'It's around times like that when you can go to an incredibly, incredibly unwell person and they will be deteriorating in front of you and you know that actually I'm probably not going to get a truck for another half an hour. What do I do?' Nick

'the paramedic had used up all his morphine... I felt so bad for this kid... he was in lots of pain and just basically lying on the floor and we couldn't do anything. I felt bad.' David

What they also noted, though, was the seemingly infinite resource of compassion:

'he (the medic) cares so much and it comes across. Considering the amount that he's seen and his experience, it's still,-_it's so fresh and genuine which is lovely to see.' David
Some students were concerned that they could not live up to the high standards set them by their colleagues.

'They (the paramedics) are always compassionate and caring, which I think is incredible really. Sometimes I think, actually, I don't know if I would be able to be that...understanding.' Nick

The way students describe themselves on scene and the note they take of their seniors' behaviour suggests that they develop an image of an ideal practitioner which they feel they might struggle to become.

\section{The complexity of debrief}

Social support is considered to be protective for all forms of work-related distress. Within their discussions about debriefing in response to the question 'Who do you talk to?' students described a multilayered process encompassing formal Death and Disability meetings, informal debriefs on shift, informal debrief with fellow PCP and PHM students, debrief with paramedic colleagues and with family. Some students wanted to talk to family members:

'I phone my mum....after every traumatic shift' Caitlin

But some believed that this was inappropriate and unhelpful since it required managing the emotional upset of others when it was comfort and understanding they needed:

'Just sit down and understand and go, yeah, that's crap... talk me through it. Get everything out.' Nick

All the participants described debrief as 'important' in allowing them to make sense of what had happened on scene. It was seen as something that should take place in a timely manner and with appropriate seriousness. Although friends on the course were a great source of support, debrief with a clinician was the optimum:

'we (paramedic and student) went and sat down...we just properly spoke it through. I feel very at ease with that one now. I think it needs to be spoken about on the day or the day after...otherwise I just feel like I have this niggly feeling that it's going to come out' Caitlin

'They know exactly what happened and you can say, well why did we decide to do this...then suddenly there is some kind of scientific underpinning, understanding that helps you process what's happened' Nick

That said, debriefing conversations were not always easy to come by. All the students noted that the doctors were very busy, and one described herself as feeling 'on the periphery' (Sarah) of some of the informal support systems. Those who had good relationships, especially longer term relationships, with colleagues explained that these were essential in facilitating debrief:

'I think our relationship is quite nice in that he can tell when I am still processing things quite a while afterwards.' Nick

One student felt very strongly that debriefing was hard work:

'You've got to make the effort, I find I have to make the effort. If I'm going to talk about it, I need to talk about it properly.' Sarah

The same student later added:

'for me that was quite a big step to say that like, hey, actually I need to talk about this.' Sarah

Of the five students in the study, each had an idea about what could address the issue of debrief being challenging. Three of the five students felt they should be 'obliged to have the opportunity' (Sarah) to talk, whereby they would be expected to attend 
regular meetings so that if they were distressed there would be a designated space to talk:

'it needs to be a system where people don't feel any apprehension in approaching it at all.' Maria.

Maria suggested that a standardised system would not work, but that there should be a culture of openness:

'If you're in the environment with the sort of people who do that every day, then you'll feel... it will be very natural to be able to talk...' Maria

Sarah pointed out that 'it's only in hindsight that I figured I was upset' and 'I can't put my finger on what I would have wanted' which highlights the need for regular debrief to be a standard part of practice. Maria had the sense that 'their (HEMS) support network for each other's quite good up there' but that because students were moving from service to service, they missed the opportunity to debrief in a more stable team.

\section{DISCUSSION}

From these interviews, it would seem that the concept of moral injury resonates with the students' experience; they are troubled by scenes which they have witnessed, both in terms of how the event has come about and its consequences for the lives of patients and families. They have a sense that while there are challenges to having sufficient material resources to deliver appropriate care, the human resources are well covered; that said, some students worry that they cannot live up to the standards they believe are required for them. They are aware of the importance and utility of talking about their experiences, even if they sometimes find it hard to do so.

It has been suggested that the amount and quality of social support available at the time of the morally injurious event can reduce its impact but the nature of moral emotions such as shame or guilt may lead people to avoid social contact. ${ }^{1}$ The inability to effectively reconcile events with beliefs and the potential for unresolved feelings of guilt and shame about perceived failures can lead to the intrusive thoughts and feelings which are symptoms of moral injury. ${ }^{22}$ What these data also suggest is that the systems which should be protective for practitioners are not as accessible as might be imagined. The perception of colleagues as more robust than oneself or as too senior as to be accessible means that some opportunities for exploring the impact of practicing this type of medicine may be missed. Compassionate responses from more senior colleagues meant that the residents in Abedeni et al's ${ }^{23}$ study felt better able to recover from their feelings of burnout. Perhaps due to the nature of prehospital medicine, not all students in this study felt able to access these interactions easily with senior colleagues.

Despite evidence that there is a dose-response relationship for traumatic exposure (see eg, Mullett-Hume et $a l^{24}$ ) in this study participants' perceptions of themselves as becoming more experienced and knowledgeable about trauma medicine and feeling more competent on scene seemed to relieve some of their feelings of distress. Research in the field of social cognitive neuroscience has demonstrated that neural responses to witnessing pain are dampened in physicians compared with non-physicians. ${ }^{13} 14$ However, it is unclear whether or not this downregulation is problematic or in fact constitutes an adaptive strategy to mitigate 'empathic distress' and promote helping behaviours when exposed to acute suffering and how this relates to physicians' psychological distress and levels of coping in the longer term. Developing experimental paradigms for future research relevant to this group of healthcare practitioners and combining them with self-report questionnaires and behavioural tasks can help to establish whether emergency medicine teams show dampened neural responses to traumatic situations, how responses may change over time and how these relate to levels of distress, coping and the ability to effectively and compassionately carry out their job. In addition, the impact of potential moderators such as years of experience or features of the situation can be examined.

This study has limitations, the number of participants is small, it is exploratory, ongoing work and the accounts presented here are by no means exhaustive. The students who took part are involved in prehospital care and a taught course in prehospital medicine and are thus different from students in other disciplines and professionals who have completed their training. Naturally those students who want to talk are those who would volunteer to take part in interviews and focus groups. It would be useful to explore the experience of the more recalcitrant students, and it may be that a non-face to face data collection method would be more suitable for this. The authors of this paper would like to undertake further qualitative and quantitative research across professional groupings in order to explore the lived experience of providers of emergency medicine and the potential effects on the brain and to develop interventions which could mitigate these effects.

Contributors EM conceived of and designed the study, collected the data, analysed it and wrote the first draft of the short report. EM has redrafted the article in collaboration with CK and DG and approved the final manuscript. CK collaborated in the conception of the study as it relates to cognitive neuroscience. CK wrote those parts of the short report relating to cognitive neuroscience and has redrafted the work for important intellectual content and approved the final manuscript. DG provided expert guidance in the conception of the study with regard to the field of emergency medicine. DG has contributed to drafts of the report from this perspective and approved the final manuscript. All three coauthors to be accountable for all aspects of the work in ensuring that questions related to the accuracy or integrity of any part of the work are appropriately investigated and resolved.

Funding The authors have not declared a specific grant for this research from any funding agency in the public, commercial or not-for-profit sectors.

Competing interests None declared.

Patient consent Not required.

Ethics approval Queen Mary Ethics of Research Committee.

Provenance and peer review Not commissioned; externally peer reviewed.

Data sharing statement Redacted interview and focus group transcripts are available on request from the corresponding author.

Open access This is an open access article distributed in accordance with the Creative Commons Attribution Non Commercial (CC BY-NC 4.0) license, which permits others to distribute, remix, adapt, build upon this work non-commercially, and license their derivative works on different terms, provided the original work is properly cited, appropriate credit is given, any changes made indicated, and the use is non-commercial. See: http://creativecommons.org/licenses/by-nc/4.0/.

\section{REFERENCES}

1 Litz BT, Stein N, Delaney E, et al. Moral injury and moral repair in war veterans: a preliminary model and intervention strategy. Clin Psychol Rev 2009;29:695-706.

2 Shay J. Moral injury. PsychoanalPsychol 2014;31:182-91.

3 Jameton A. Nursing practice: the ethical issues, 1984.

4 Fourie C. Who is experiencing what kind of moral distress? distinctions for moving from a narrow to a broad definition of moral distress. AMA J Ethics 2017;19:578-84.

5 Sendler DJ, Krukowska A, Makara-Studzinska M. How the exposure to trauma has hindered physicians' capacity to heal: prevalence of PTSD among healthcare workers. EurJPsychiat 2016:30:321-34.

6 Roden-Foreman JW, Bennett MM, Rainey EE, et al. Secondary traumatic stress in emergency medicine clinicians. Cogn Behav Ther 2017;46:1-11.

7 Sheck A. Special report: lurking inside every headline, PTSD for emergency physicians. Emergency Medicine News 2013;35:18-19.

8 American Psychological Association Diagnostic and Statistical Manual of Mental Disorders (DSM-5). 5th ed, 2013 


\section{Original article}

9 Zoellner LA, Bedard-Gilligan MA, Jun JJ, et al. The evolving construct of Posttraumatic Stress Disorder (PTSD): DSM-5 Criteria Changes and Legal Implications. Psychol Inj Law 2013;6:277-89.

10 Lemaire JB, Wallace JE. Burnout among doctors: a system level problem requiring a system level response. BMJ 2017;358:j3360.

11 Maslach C, Jackson SE. The measurement of experienced burnout. JOrganBehav 1981;2:99-113.

12 Hooper C, Craig J, Janvin DR, et al. Compassion satisfaction, burnout and compassion fatigue among emergency medicine nurses compared with Nurses in other selected inpatient specialties. J Emerg Nurse 2010;36:420-7.

13 Decety J, Yang C-Y. \& Cheng Y, Physicians down-regulate their pain empathy response: An event-related brain potential study. Neurolmage;201050:1676-82.

14 Cheng Y, Lin CP, Liu HL, et al. Expertise modulates the perception of pain in others. Curr Biol 2007;17:1708-13.

15 Gleichgerrcht E, Decety J. The relationship between different facets of empathy, pain perception and compassion fatigue among physicians. Front Behav Neurosci 2014;8.

16 American psychological association clinical practice guideline for the treatment of Posttraumatic Stress Disorder (PTSD) in Adults. https://www.apa.org/ptsd-guideline/ ptsd.pdf (accessed Sep 2017).
17 Crumpei I, Dafinoiu I. Secondary traumatic stress in medical students Procedia. SocBehavSci 2012;46:1465-9.

18 Currier JM, Holland JM, Drescher K, et al. Initial psychometric evaluation of the Moral Injury Questionnaire--Military version. Clin Psychol Psychother 2015;22:54-63.

19 Patton MQ. Qualitative evaluation and research methods. 2nd edn. Newbury Park, California: Sage, 1990.

20 Clarke V, Braun V. Teaching thematic analysis: overcoming challenges and developing strategies for effective learning. Psychologist 2013;26:120-3.

21 Clarke V, Braun V. Using thematic analysis in psychology. QualResPsychol 2006;3:2.

22 Nieuwsma JA, Walsmer RD, Farnsworth JK. Possibilities within acceptance and commitment therapy for approaching moral injury. CurrPsychiatryRev 2015:11:193-206.

23 Abedeni NC, Stack SW, Goodman JL, et al. "It's not just time off": a framework for understanding factors promoting recovery from burnout among internal medicine residents. J Grad Med Educ 2018.

24 Mullett-Hume E, Anshel D, Guevara V, et al. Cumulative trauma and posttraumatic stress disorder among children exposed to the 9/11 World Trade Center attack. Am J Orthopsychiatry 2008;78:103-8. 